\title{
Reanalysis of U.S. National Weather Service Flood Loss Database
}

\author{
Mary W. Downton ${ }^{1}$; J. Zoe Barnard Miller²; and Roger A. Pielke Jr. ${ }^{3}$
}

\begin{abstract}
To understand the nature of increasing flood damage in the United States, accurate data are needed on costs and vulnerability associated with flooding. The National Weather Service (NWS) is the only organization that has maintained a long-term historical record of flood damage throughout the country. The NWS estimates are obtained from diverse sources, compiled soon after each flood event, and not verified by comparison with actual expenditures. This paper presents results of a comprehensive reanalysis of the scope, accuracy, and consistency of NWS damage estimates from 1926 to 2000 and recommends appropriate methods for data use and interpretation. Estimates for individual flood events are often quite inaccurate, but when estimates from many events are aggregated the errors become proportionately smaller. With the precautions described in this paper, the reanalyzed NWS damage estimates can be a valuable tool to aid researchers and decision makers in understanding the changing character of damaging floods in the United States. The reanalyzed data are available at http://www.flooddamagedata.org/.
\end{abstract}

DOI: 10.1061/(ASCE)1527-6988(2005)6:1(13)

CE Database subject headings: Flood damage; Economic factors; Cost estimate; Databases; National Weather Service.

\section{Introduction}

The National Weather Service (NWS) estimates that flooding caused approximately $\$ 50$ billion damage in the United States in the 1990s, in current dollars (NWS 2004). Although flood damage fluctuates greatly from year to year, estimates indicate an increasing trend over the past century (Pielke and Downton 2000). To understand increasing damage and assess implications for policy, decision makers need to recognize the influences of climate, population growth, land use, and policy on trends in damage. An increase in flood damage due to changing climate would probably require different policy actions than would damage increases due to implementation of flood policies.

The available records of historical flood damage are inadequate for policy evaluation, scientific analysis, and disaster mitigation planning (NRC 1999; Heinz Center 2000; Changnon 2003). There are no uniform guidelines for estimating flood losses, and there is no central clearinghouse to collect, evaluate, and report flood damage. The data that exist are rough approximations, compiled by the NWS from damage estimates that are reported in many different ways. Moreover, most published summaries of the damage estimates focus primarily on aggregate national damage totals.

\footnotetext{
${ }^{1}$ Associate Scientist, National Center for Atmospheric Research, P.O. Box 3000, Boulder, CO 80307. E-mail: downton@ucar.edu

${ }^{2}$ Graduate Research Assistant, National Center for Atmospheric Research, P.O. Box 3000, Boulder, CO 80307. E-mail: kennzoe@centurytel.net

${ }^{3}$ Director, Center for Science and Technology Policy Research, Univ. of Colorado, Boulder, CO 80309. E-mail: pielke@cires.colorado.edu

Note. Discussion open until July 1, 2005. Separate discussions must be submitted for individual papers. To extend the closing date by one month, a written request must be filed with the ASCE Managing Editor. The manuscript for this paper was submitted for review and possible publication on December 6, 2002; approved on July 20, 2004. This paper is part of the Natural Hazards Review, Vol. 6, No. 1, February 1, 2005. (C)ASCE, ISSN 1527-6988/2005/1-13-22/\$25.00.
}

Scientists need historical flood damage data at a variety of spatial scales to analyze variations in flood damage and what contributes to them. For example, during El Niño years, southern California receives more precipitation than in the typical year. Conventional wisdom suggests that the increase in precipitation should result in an increase in damaging floods. If California's emergency planners knew this to be the case, they could prepare for the floods that come with El Niño, possibly reducing damage. (Or, if the conventional wisdom were shown to be wrong, then emergency managers would likely want to alter their decisions accordingly.) Scientists looking for a causal relationship would need sub-state-level damage data to determine to what degree historical high-damage years in southern California are associated with El Niño events.

Social scientists looking at the effect of policies designed to reduce flood damage also need access to historical data at regional and local scales. For example, the National Flood Insurance Program was created in 1968 to "assist in reducing damage caused by floods" [42 U.S.C. §4102(c)(3)]. Researchers evaluating the program would like to isolate the effect of the program from all other factors influencing flood damage in particular areas. At the river basin or community level, the effect of a federal policy implemented in 1968 might be isolated and measured. In sum, historical damage data are essential for any study that seeks to understand the role that climate, population growth, and government policies play in determining trends in flood damage.

Ideally, a national database of historical flood damage would cover the entire country over a long time period, using consistent criteria and methods in all times and places. The NWS is the only organization that has maintained a long-term and fairly comprehensive record of flood damage throughout the United States. Insurance company records include only insured property, and records of the Federal Emergency Management Agency (FEMA) include only property that qualifies for federal assistance in presidentially declared disasters. Few state and local governments maintain damage records beyond those required by FEMA; only in newspaper archives from cities and towns across the nation 
might one find more complete historical reporting of local flood damage.

This paper presents results of a reanalysis of NWS flood damage estimates from 1926 to 2000. It describes NWS methods of collecting flood damage estimates, explains some of the limitations and problems in the data, and recommends appropriate methods of interpretation and use. Objectives of the reanalysis were to (1) assemble a national database of historical flood damage based on NWS damage estimates, making it as complete and consistent as possible; (2) describe what the estimates represent; (3) evaluate the accuracy and consistency of the estimates; and (4) develop guidelines for use of the data and make the data widely available to users.

The writers reviewed and evaluated NWS flood damage data sets by examining archived information, interviewing people who collect the data, identifying sources of error and inconsistency, and performing error analyses. Corrections were made in the estimates only when changes could be clearly justified based on published sources or information in NWS files. The following data sets resulted from the study and are available from 〈http:// www.flooddamagedata.org $\rangle$.

1. Estimated flood damage in the United States (1926-1979 and 1983-2003 by fiscal year);

2. Estimated flood damage for each state in the United States (1955-1979 by calendar year and 1983-2003 by fiscal year); and

3. Estimated flood damage by river basin and drainage for the United States (1933-1975 by calendar year).

\section{National Weather Service Flood Damage Estimates}

The NWS has published flood damage estimates almost annually since 1933. Initially, reporting units were defined by river basins, but annual summaries of damage by state were provided beginning in 1955. Consistent administration, methodology, and format of the published reports suggest that these data form a reasonably homogeneous time series. The long-term consistency in collection of flood damage data results from its connection to weather forecasting and storm warning operations of the NWS. Since at least 1950, NWS offices across the United States have submitted reports on severe storms to NWS headquarters. The reports include descriptions of severe storms and associated deaths and damage. In fact, the data may not be as reliable as they might appear.

From 1976 through 1979, NWS reports indicate that reduction of funding led to cutbacks in the compilation of flood damage data. Data collection continued as in prior years, but there appears to have been less checking and updating of initial damage information. Further, publication of annual summaries ceased. In 1980, compilation of flood damage estimates was discontinued entirely.

In 1983, Congress ordered the U.S. Army Corps of Engineers (USACE) to provide annual reports of U.S. flood damage. The USACE contracted with the NWS Hydrologic Information Center (NWS-HIC) to provide the required data and has published NWS estimates of flood damage in each state annually since 1983.

Historically, field office personnel obtained their damage estimates primarily from newspapers (P. Polger, NWS, personal communication, (February 16, 2000). Today, information from newspapers is supplemented by estimates obtained through a variety of contacts such as emergency managers, insurance agents, and local officials. If a flood has received a presidential disaster declaration, information can be obtained from damage assessments by FEMA storm survey teams that travel to the flood scene. Estimates of damage to insured property can be obtained from local insurance agents, but the estimation process is not performed with rigorous attention to accuracy. One field office representative described using the following procedure: Since the largest insurer handles about $25 \%$ of the insured property in the local area, an estimate of insured losses is obtained by getting a cost estimate from that insurer and multiplying by four. A full survey of each damaged structure does not take place; instead, in many cases a simplifying formula is used to estimate damage. Crop damage estimates are obtained from U.S. Department of Agriculture (USDA) agents or from monthly reports on claims made by farmers to the USDA (J. Ogren, NWS, personal communication, August 29, 2001).

The field office reports have been published monthly since 1959 in a National Oceanographic and Atmospheric Administration (NOAA) periodical, Storm Data. The reports are filed soon after the storm events and receive only minimal quality control before publication; thus the damage estimates provided in Storm Data are preliminary and incomplete. Staff at NWS headquarters use the field office reports as a starting point for compiling more complete flood damage estimates. Based on summaries of severe weather and flood events, they request additional information from the field offices and perform considerable checking to produce their final damage estimates. Thus, the flood damage estimates provided by the NWS and used in our study differ from those published in Storm Data.

\section{Sources of Historical National Weather Service Estimates}

The NWS and the U.S. Weather Bureau (WB) published flood reports regularly in five publications from 1918 through 2001. Table 1 summarizes the time periods covered and the information provided by each of these sources. In the early years, damage estimates were published only after major flood events. Annual reporting of flood damage throughout the United States commenced in 1933.

From 1934 to 1975, the River and Flood Service published monthly flood reports and annual summaries of flood damage by river basin, first in the Monthly Weather Review and later in the Climatological Data National Summary. Two formats were consistently used for the annual summaries, one during 1934-1947, the other during 1948-1975. Annual damage estimates by state for calendar years 1955-75, and monthly damage estimates for the nation during 1925-1975, were calculated and published in later reports (NWS 1977).

After publication of damage summaries was phased out in the late 1970s, for several years the only published NWS records of flood damage were those included in Storm Data monthly reports. As noted above, these reports often were incomplete and received little checking. Most damage estimates were indicated only by marking a damage category (for example, " $\$ 500,000$ to $\$ 5$ million" or “\$50 million to $\$ 500$ million").

In 1983, when Congress asked the USACE for annual reports of flood damage, Storm Data was the only available nationwide source of damage estimates. Under contract to USACE to provide estimates, NWS-HIC compiled the limited information available. In the years that followed, methods of compiling and checking the estimates were developed. These estimates are published annually in the U.S. Army Corps of Engineers Annual Flood Damage Report to Congress (USACE 1984). 
Table 1. Published Sources of Flood Damage Estimates from National Weather Service and U.S. Weather Bureau

\begin{tabular}{|c|c|c|c|c|}
\hline Publication & $\begin{array}{l}\text { Years damage } \\
\text { reported }\end{array}$ & $\begin{array}{c}\text { Spatial } \\
\text { aggregation }\end{array}$ & $\begin{array}{l}\text { Time periods } \\
\text { summarized }\end{array}$ & Information provided \\
\hline $\begin{array}{l}\text { Report of Chief of the } \\
\text { Weather Bureau }\end{array}$ & 1918-1933 & River basin & $\begin{array}{c}\text { Water year } \\
\text { (October-September) }\end{array}$ & $\begin{array}{c}\text { Describes large flood events and occasionally gives damage } \\
\text { estimates for individual large events }\end{array}$ \\
\hline $\begin{array}{l}\text { Monthly Weather Review } \\
\text { (WB, 1934-1949) }\end{array}$ & 1933-1977 & River basin & Calendar year & $\begin{array}{c}\text { Annual summaries describe damage in major floods and list } \\
\text { damage estimates for all major river drainages }\end{array}$ \\
\hline $\begin{array}{l}\text { Climatological Data National } \\
\text { Summary } \\
\text { (WB, NOAA, 1950-1977) }\end{array}$ & 1948-1977 & River basin & Calendar year & $\begin{array}{l}\text { Monthly summaries describe damage in "notable" floods. } \\
\text { Until 1975, annual summaries list damage for major river } \\
\text { drainages. General summary for } 1975 \text { gives state damage by } \\
\text { calendar year, 1955-1975, national damage by month, } \\
1925-1975\end{array}$ \\
\hline $\begin{array}{l}\text { Storm Data } \\
\text { (WB, NOAA) }\end{array}$ & 1959-present & $\begin{array}{l}\text { County or } \\
\text { multicounty area }\end{array}$ & - & $\begin{array}{l}\text { Monthly reports on storm events sometimes briefly describe } \\
\text { damage. Estimated damage checked off on logarithmic scale } \\
\text { until 1994, reported in thousands of dollars since } 1995\end{array}$ \\
\hline $\begin{array}{l}\text { Annual Flood Damage } \\
\text { Report to } \\
\text { Congress (USACE) }\end{array}$ & 1983-present & State & $\begin{array}{l}\text { Federal fiscal year } \\
\text { (October-September) }\end{array}$ & $\begin{array}{l}\text { Annual reports describe major floods and list damages } \\
\text { suffered by state; recent reports give } 10 \text {-year summary } \\
\text { tables of damage and deaths, by state }\end{array}$ \\
\hline
\end{tabular}

\section{Reanalysis of Estimates}

Data used in our study and access to historical archives were provided by NWS-HIC staff. We obtained additional information from staff members at the NWS and state emergency management offices, as well as independent damage estimates from reports of federal and state agencies. We corrected clerical errors by comparing the data with published sources and archived material. Where two equally plausible estimates existed (for example, the end points of the damage categories used in Storm Data), we used the geometric mean in order to minimize proportional errors.

We made intensive efforts to collect supplementary flood damage estimates for 1976-1982, and data and confirmatory evidence were found to complete state and national damage estimates for 1976-1979 (in 1979, a few states did not have individual estimates but are included in multistate regions). However, little data were available for 1980-1982, and large errors were found in the rough approximations supplied by NWS-HIC; therefore, estimates for 1980-1982 are not included in the reanalyzed data sets.

\section{Consistency of Data Series over Time}

Published NWS reports of flood damage are uniform in format and content for extended periods, indicating that fairly consistent methods were used within the periods 1934-1979 and 19832000. Before 1980, estimates were compiled by river basin and presented by calendar year, but since 1982 they have been compiled by state and presented by fiscal year. Little is known about the methods used to compile and check the estimates prior to 1980. The published reports themselves show an intent to include all parts of the United States and all types of physical damage.

NWS policies on what losses to include have changed somewhat over the years. Damage estimates published through 1975 focused primarily on damage to property and crops, but included some indirect losses. Present policy is to focus exclusively on physical damage to property and crops. Until 1992, separate estimates were given for property and agricultural damage, but in 1993 that distinction was eliminated.

It is often impossible to separate damage by flood and that from other storm-related causes. Typically, the NWS labels the full amount as flood damage if heavy rain or river flows are considered the primary cause. Conversely, flood damage may be omitted if the major cause is wind (hurricanes, tornadoes), hail, snow, or ice. These uncertainties can lead to incompatibility with data from other sources.

The NWS process of collecting damage data has always focused more attention on larger floods. At least since 1990, intensive efforts have been made to obtain estimates in floods that appear to involve over \$1 million damage. However, the field offices differ greatly in the amount of effort put into collecting damage estimates. Damage in small floods is frequently underestimated or ignored.

In the writers' judgment, the general approach of the NWS to collecting flood damage estimates has been reasonably consistent from 1934 to the present, although the coverage of smaller floods may have varied over time. Somewhat larger errors can be expected in the estimates for 1976-1979 and 1983-1984 because of the curtailment of data collection and the need to establish new procedures when reporting resumed in 1983.

The reanalyzed data sets present national damage estimates by fiscal year (October-September, corresponding to water years) for the entire period. It is not possible to do the same for state estimates, and therefore they are presented by calendar year for 1955-1979 and by fiscal year for 1983-2000. River basin estimates (available only for 1933-1975) are presented by calendar year.

\section{Accuracy of Estimates}

Potentially the most serious source of error is the lack of systematic, reliable methods in the NWS field offices for obtaining damage estimates. Staff who collect the estimates have little or no training in damage estimation and rely on diverse sources. Estimation methods used by their sources are unknown, and estimates are usually finalized at NWS headquarters within three months after a flood event and are not compared with records of actual damage costs. An overall tendency to underestimate total damage is expected because of incomplete reporting and the omission of some floods.

Ideally, estimation errors would be measured by systematically comparing estimates with actual costs, which often are not known until long after a flood event. Unfortunately, actual loss data are seldom collected in a form that can be compared with estimates made at the time of the flood. This study analyzed estimation 


\section{Flood Damage Estimates in Five States (millions of 1995 dollars)}

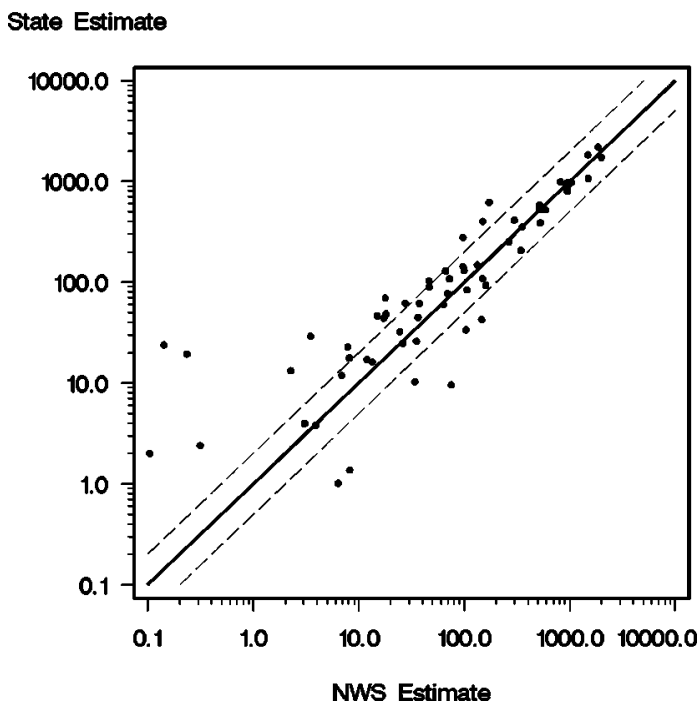

Fig. 1. Flood damage estimates provided by five states versus NWS estimates in same years

errors in two ways, first by comparing county-level estimates with actual costs in a large flood disaster (the 1998 California El Niño disaster), then by comparing annual NWS estimates with independent damage estimates provided by five states, as reported by Pielke et al. (2002) and Downton and Pielke (2005).

Fig. 1 illustrates the comparison of state and NWS damage estimates; all dollar amounts are reported in inflation-adjusted 1995 dollars. The state estimates were provided by California (1955-1998), Colorado (1955-1998), Michigan (1975-1998), Virginia (1977-1998), and Wisconsin (1973-1993). Of the 155 years covered by the state data sets, the scatterplot shows those years that have nonzero estimates from both the NWS and the state. Logarithmic scales are used on the axes to highlight proportional differences in the estimates. The solid diagonal line represents perfect agreement between the estimates. Data points outside of the two dashed lines are cases in which the estimates differ by more than a factor of two. The closest agreement between state and NWS estimates occurs in floods involving major damage (over $\$ 500$ million). At the other extreme, the largest proportional disagreements (cases farthest outside the dashed lines) occur when both sources indicate that flood damage was relatively low (under $\$ 50$ million).

The two comparisons, although not definitive, suggest the following conclusions:

1. Individual damage estimates for small floods or for local jurisdictions within a larger flood area tend to be extremely inaccurate.

2. Damage estimates become more accurate at higher levels of aggregation; thus NWS estimates summed over large geographic areas or many years are likely to be reasonably reliable (within about a $40 \%$ margin of error).

3. Floods causing relatively low damage (up to $\$ 50$ million) are occasionally omitted, or their damage greatly underestimated, in the NWS data sets. Researchers studying flood damage in states or river basins should be aware that the NWS estimates occasionally overlook some locally significant damage.

\section{Interpretation and Use of Reanalyzed Data}

Despite their defects, the reanalyzed NWS damage estimates are the best available nationwide data sets, so it is important to understand their inconsistencies and determine appropriate uses. These data sets contain valuable information about historical flood damage in the United States, but in interpreting them, users should be aware of their lack of precision and the importance of social context. This section suggests methods of analysis that guard against misleading results.

At the national level, NWS flood damage estimates have been compiled and published systematically in most years since 1934, and substantial flood damage has occurred every year. The above findings suggest that annual damage totals are reasonably accurate because they are sums of estimates from many flood events.

At the state level, however, annual damage estimates are more problematic. Since flood damage does not occur every year, both frequency and magnitude of damage must be considered. Annual damage estimates for a state are usually below $\$ 500$ million (in 1995 dollars), and therefore the above findings indicate these estimates are likely to contain proportionately large errors.

The frequency distribution of national flood damage estimates during 1934-2000 approximates a lognormal distribution (that is, the logarithms of the annual damage estimates fit a normal distribution, based on the Shapiro-Wilk test). Likewise, in most states the nonzero flood damage estimates during 1955-2000 approximate a lognormal distribution. Therefore, conventional parametric statistics can be used to analyze the damage estimates.

\section{Analyzing Trends over Time at National Level}

There are several ways of looking at trends in flood damage. Economic damage results from an interaction between flood waters and human activities in the flooded area, so one must consider changes in population and development. Fig. 2 shows the U.S. total flood damage, flood damage per capita, and flood damage per million dollars of tangible wealth.

Fig. 2 uses the reanalyzed damage data to recreate graphs similar to those shown by Pielke and Downton (2000); all estimates are adjusted for inflation. Damage per capita is computed by dividing the inflation-adjusted losses for each year by the estimated population on July 1 of that year (www.census.gov). Damage per million dollars of tangible wealth is based on the net stock of fixed reproducible tangible wealth as estimated by the U.S. Department of Commerce, Bureau of Economic Analysis (www.bea.doc.gov). Thus, the damage per million dollars of tangible wealth reflects the proportion of the nation's wealth in that year lost due to floods.

The three graphs give quite different pictures of trends in U.S. flood damage. Total damage and per capita damage have increased significantly since 1934 (statistically significant at a 95\% confidence level). On the other hand, damage per unit wealth has declined slightly (although the trend is significant only at an $85 \%$ confidence level). The three measures suggest different conclusions about trends in U.S. flood damage.

\section{Frequency of Damaging Floods at State Level}

Many states experience damaging floods rather infrequently, and few states report flood damage every year. However, the lack of a damage estimate does not necessarily imply zero flood damage because reporting of dollar damages, particularly in small flood events, is somewhat unreliable. To compare the frequency of 
(a) U.S. Total Food Damage, 1934-2000

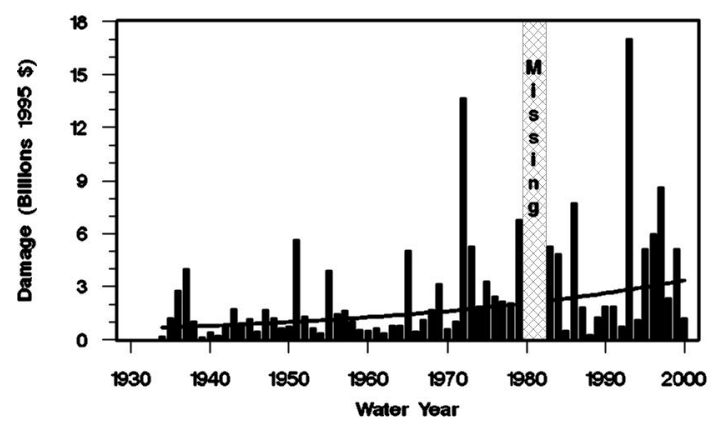

(b) US. Per Capita Food Damage, 1934-2000

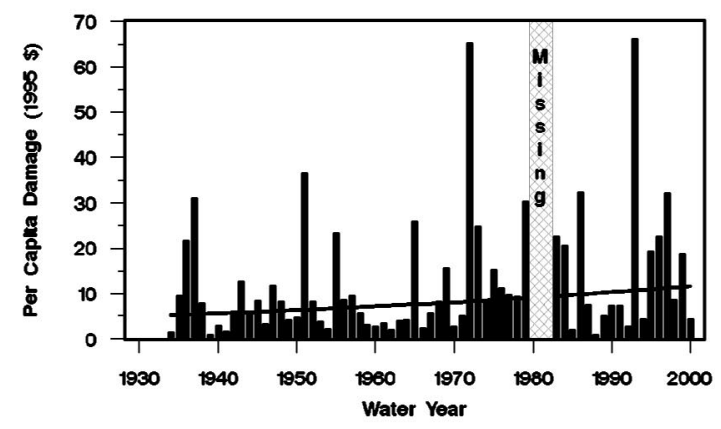

(c) US. Food Damage per Unit Wealth, 1934-1998

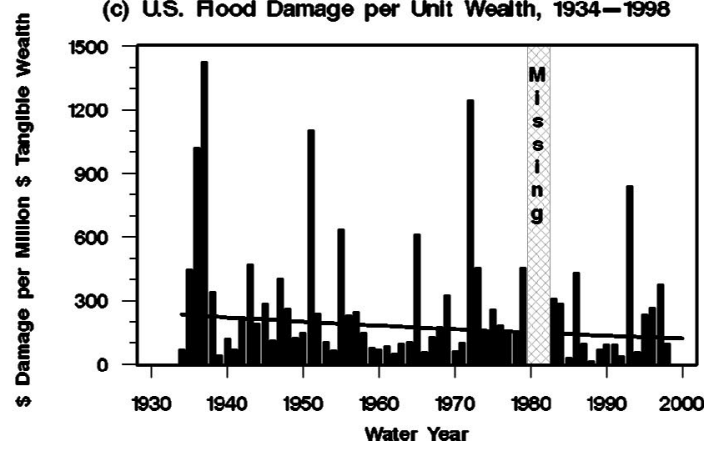

Fig. 2. Estimated annual flood damage in United States, 1934-1999: (a) total flood damage; (b) flood damage per capita; (c) flood damage per million dollars of tangible wealth. Trend lines are transformations of linear trends computed on logarithms of damage values

damaging floods across different times and locations, it would be important to know what levels of damage were reported fairly consistently. Comparison of frequency distributions of state flood damage estimates before and after 1980 indicates that the NWS did not consistently report flood damage below \$100,000 (in 1995 dollars) in the earlier period (Pielke et al. 2002).

The NWS defines its flood damage data as "loss estimates for significant flooding events" (NWS 2004). Floods that cause deaths or extensive damage have always received the most attention, but the records do not indicate any formal criteria for deciding which floods to include. When pressed for a definition of which floods are "significant" enough that intensive efforts are made to obtain complete estimates, NWS-HIC director Frank Richards (personal communication, June 27, 2001) offered a rough guideline of at least $\$ 1$ million in losses. This applies to NWS practice since 1990, but earlier guidelines, if used, are unknown.

\section{Magnitude of Damages at State Level}

States differ greatly, both in flood frequency and in the amount of damage caused by a "typical" flood event. Fig. 3 shows the esti-

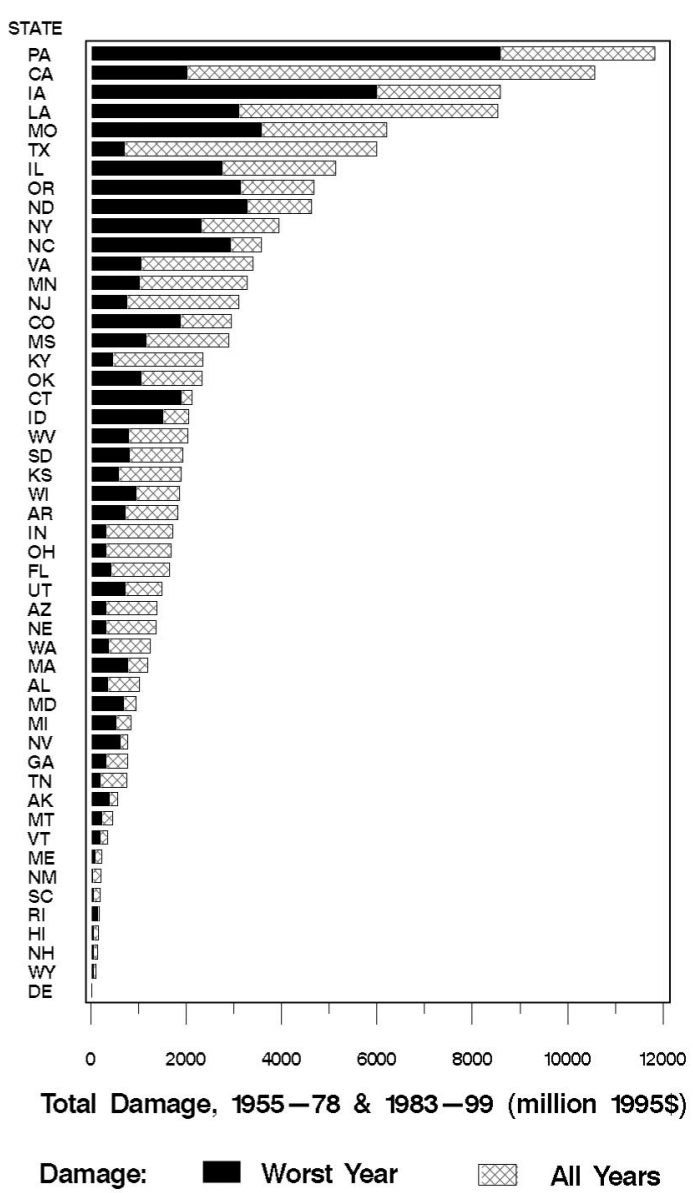

Fig. 3. States ranked by estimated total damage (in millions of 1995 dollars) during 1955-1978 and 1983-1999

mated total damage for each state during the years 1955-1978 and 1983-1999, as well as the damage in the worst flood year. A few states have had many major floods (e.g., California, Texas), while many others have suffered most of their total damage in just one or two major flood events (including Pennsylvania and Iowa, among the worst in total damage). Many states had no yearly damage greater than $\$ 500$ million in this period. In 10 states, the total damage for the entire 41-year period is less than $\$ 500$ million.

These state comparisons do not include 1979 damage because some estimates for that year are available only for large regions, not for individual states. Estimates of 1979 damage are available for many states, however, and are useful to illustrate how rankings of states by total damage can differ depending on the time period covered. For example, 1979 flood damage in Texas was $\$ 3.76$ billion-substantially greater than in any of the years covered in Fig. 3. Texas would move from sixth to third place in the rankings if 1979 were included.

The frequency distributions of flood damage in each state give another perspective on past flood vulnerability. Table 2 shows how states differ in both frequency and severity of damaging floods during 1955-1978 and 1983-1999. The states are ordered by their median annual flood damage based on all 41 years, including years with no reported damage. The number of missing, very low ( $<\$ 1$ million), and relatively high $(>\$ 100$ million $)$ 
Table 2. Comparison of Damage Estimates by State, 1955-1978 and 1983-1999

\begin{tabular}{|c|c|c|c|c|c|c|}
\hline State & Region & $\begin{array}{l}\text { Median } \\
\text { damage }\end{array}$ & $\begin{array}{c}\text { Maximum } \\
\text { damage }^{\mathrm{a}}\end{array}$ & Years with no estimate & $\begin{array}{c}\text { Years with } \\
0<\text { est } \leqslant 1.0\end{array}$ & $\begin{array}{c}\text { Years with } \\
\text { est }>100\end{array}$ \\
\hline Rhode Island & New England & 0.00 & 143.00 & 33 & 5 & 1 \\
\hline Delaware & Coastal Mid-Atlantic & 0.00 & 7.00 & 32 & 7 & 0 \\
\hline Massachusetts & New England & 0.00 & 774.00 & 25 & 5 & 2 \\
\hline New Hamphsire & New England & 0.00 & 56.00 & 23 & 6 & 0 \\
\hline Hawaii & & 0.00 & 44.00 & 23 & 2 & 0 \\
\hline Connecticut & New England & 0.00 & $1,881.00$ & 21 & 6 & 2 \\
\hline Vermont & New England & 0.00 & 194.00 & 20 & 9 & 1 \\
\hline Wyoming & Rocky Mountains & 0.05 & 53.00 & 17 & 14 & 0 \\
\hline Maine & New England & 0.06 & 77.00 & 20 & 3 & 0 \\
\hline New Jersey & Coastal Mid-Atlantic & 0.06 & 749.00 & 18 & 5 & 8 \\
\hline Alaska (29 years) & & 0.07 & 383.00 & 14 & 4 & 1 \\
\hline Maryland and D.C. & Coastal Mid-Atlantic & 0.14 & 681.00 & 15 & 14 & 1 \\
\hline Nevada & Semiarid West & 0.16 & 616.00 & 13 & 12 & 1 \\
\hline Michigan & North Lakes & 0.21 & 528.00 & 17 & 11 & 3 \\
\hline North Dakota & North Central & 0.41 & $3,280.00$ & 14 & 9 & 4 \\
\hline South Dakota & North Central & 0.51 & 796.00 & 10 & 13 & 4 \\
\hline Colorado & Rocky Mountains & 0.57 & $1,866.00$ & 11 & 10 & 4 \\
\hline South Carolina & Southeast & 0.66 & 40.00 & 5 & 18 & 0 \\
\hline New Mexico & Semiarid West & 0.73 & 34.00 & 16 & 6 & 0 \\
\hline Utah & Semiarid West & 0.84 & 712.00 & 7 & 14 & 2 \\
\hline Montana & Rocky Mountains & 1.04 & 229.00 & 10 & 10 & 1 \\
\hline Idaho & Rocky Mountains & 1.21 & $1,507.00$ & 9 & 10 & 2 \\
\hline Wisconsin & North Lakes & 1.61 & 943.00 & 11 & 8 & 4 \\
\hline Georgia & Southeast & 1.86 & 307.00 & 5 & 7 & 3 \\
\hline Virginia & Southeast & 1.91 & $1,042.00$ & 9 & 9 & 6 \\
\hline Arizona & Semiarid West & 2.27 & 306.00 & 7 & 9 & 4 \\
\hline Minnesota & North Lakes & 2.40 & $1,006.00$ & 4 & 12 & 7 \\
\hline Florida & Southeast & 2.48 & 410.00 & 6 & 9 & 5 \\
\hline North Carolina & Southeast & 3.99 & $2,919.00$ & 5 & 5 & 3 \\
\hline Oregon & Pacific NW & 4.06 & $3,143.00$ & 2 & 6 & 4 \\
\hline Washington & Pacific NW & 4.32 & 363.00 & 5 & 7 & 3 \\
\hline Louisiana & Lower Mississippi & 5.60 & $3,097.00$ & 7 & 7 & 10 \\
\hline Tennessee & Southeast & 6.01 & 193.00 & 2 & 8 & 1 \\
\hline Alabama & Southeast & 6.10 & 351.00 & 4 & 4 & 3 \\
\hline Arkansas & Lower Mississippi & 6.87 & 712.00 & 2 & 6 & 4 \\
\hline Mississippi & Lower Mississippi & 8.07 & $1,157.00$ & 1 & 3 & 4 \\
\hline West Virginia & Ohio River & 8.60 & 782.00 & 1 & 7 & 5 \\
\hline Kansas & Central Plains & 8.61 & 575.00 & 3 & 4 & 6 \\
\hline Oklahoma & Central Plains & 8.97 & $1,045.00$ & 4 & 8 & 5 \\
\hline Pennsylvania & Inland Mid-Atlantic & 10.39 & $8,590.00$ & 3 & 7 & 6 \\
\hline Nebraska & Upper Mississippi & 13.89 & 307.00 & 4 & 4 & 4 \\
\hline New York & Inland Mid-Atlantic & 14.60 & $2,305.00$ & 7 & 3 & 6 \\
\hline Illinois & Upper Mississippi & 15.31 & $2,754.00$ & 1 & 3 & 8 \\
\hline Iowa & Upper Mississippi & 17.18 & $5,987.00$ & 4 & 6 & 9 \\
\hline Kentucky & Ohio River & 17.67 & 453.00 & 1 & 7 & 7 \\
\hline Indiana & Ohio River & 19.29 & 310.00 & 0 & 3 & 3 \\
\hline Ohio & Ohio River & 22.06 & 313.00 & 3 & 5 & 4 \\
\hline Missouri & Upper Mississippi & 25.42 & $3,577.00$ & 0 & 7 & 12 \\
\hline California & & 45.64 & $2,007.00$ & 3 & 4 & 13 \\
\hline Texas & & 77.44 & 691.00 & 1 & 1 & 16 \\
\hline
\end{tabular}

Note: States are ordered by increasing median damage (all years), missing estimates are treated as zero, and all estimates are in millions of 1995 dollars. ${ }^{a}$ Estimates of maximum damage can be misleading. For example, in Idaho the maximum was caused by failure of the Teton Dam in 1976; the worst damage directly from precipitation and streamflow is estimated at $\$ 120$ million. In Texas, the maximum appears small, but much greater damage occurred in a year not covered by this table (\$3.76 billion in 1979). 


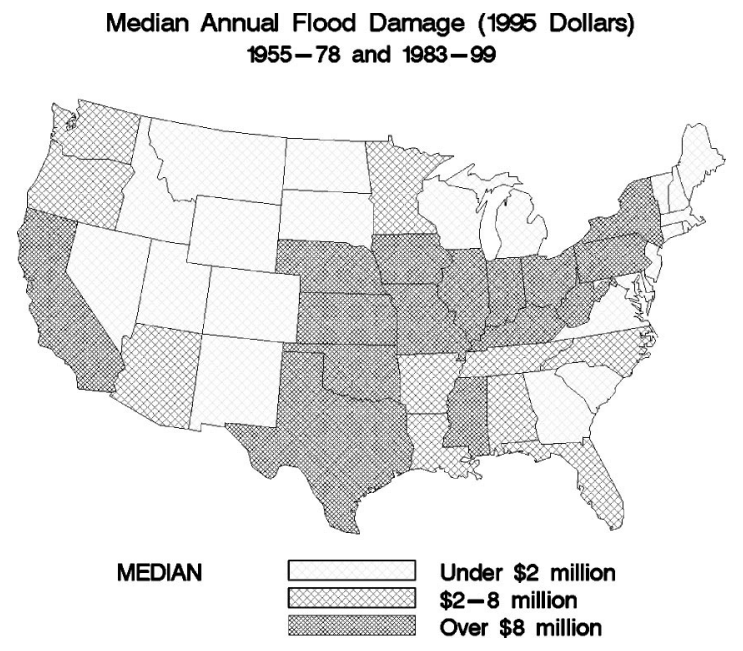

Fig. 4. Level of median annual flood damage (in 1995 dollars) in each state for 1955-1978 and 1983-1999

damage estimates are shown to indicate both frequency and relative magnitudes of flood damage. Fig. 4 shows the median damage level of each state.

To illustrate the differences between states, three "historical vulnerability categories" can be loosely defined based on flood frequency and median damage in those 41 years. Although the worst flood, indicated by maximum damage, is shown in Table 2 for each state, it is not considered in defining the historical categories.

1. Low vulnerability: Floods are relatively infrequent, and damage is less than about $\$ 2$ million in the majority of years. Includes New England states, some mid-Atlantic coastal states, and low-population states in the Rocky Mountains and the semiarid West, plus Hawaii and Alaska. Damage rarely exceeds $\$ 100$ million. (Frequency distributions of flood damage in Maine and New Mexico are surprisingly similar, despite their geographic differences.)

2. Medium vulnerability: Damaging floods occur in most years, and median damage is in approximately the \$2 million to 8 million range. Includes most states in the Southeast, the lower Mississippi basin, and the Pacific Northwest. Most of these states have few instances of flood damage over $\$ 100$ million (Louisiana is a notable exception).

3. High vulnerability: Damaging floods occur in most years, and damage exceeds about $\$ 8$ million in the majority of years. Includes states in the upper Mississippi, Missouri, and Ohio basins, parts of the mid-Atlantic region, California, and Texas. Flood damage over $\$ 100$ million occurs relatively frequently, especially in Missouri, California, and Texas.

States typical of the three vulnerability categories are shown in Figs. 5(a-c) and Table 3. California represents the highvulnerability states, Alabama the medium vulnerability states, and Maine the low-vulnerability states. In all three states, estimated damage totals for the full 41 years (Table 3 ) would be affected little by occasional omission of damage under \$1 million. Indeed, California and Alabama totals would be affected little by a few \$25 million omissions. But in Maine, a \$25 million flood is relatively large, representing over $10 \%$ of total damage. Its omission could greatly influence the result of, say, a comparison of damages during two time periods. Furthermore, since floods in Maine involve relatively low damage, there is less aggregation of dam- (a) California Flood Damage

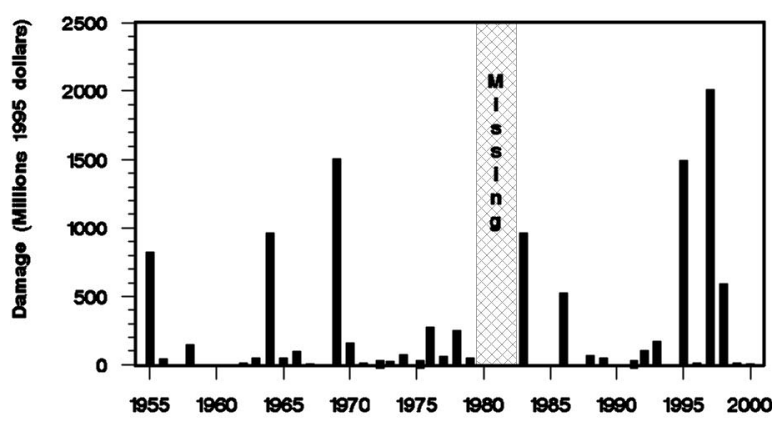

(b) Alabama Flood Damage

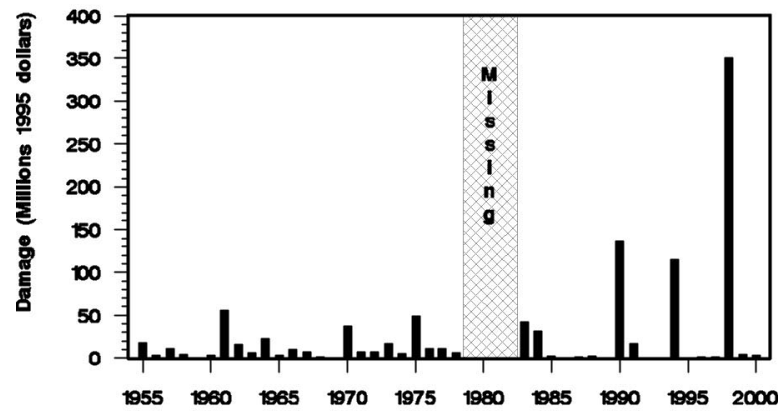

(c) Maine Flood Damage

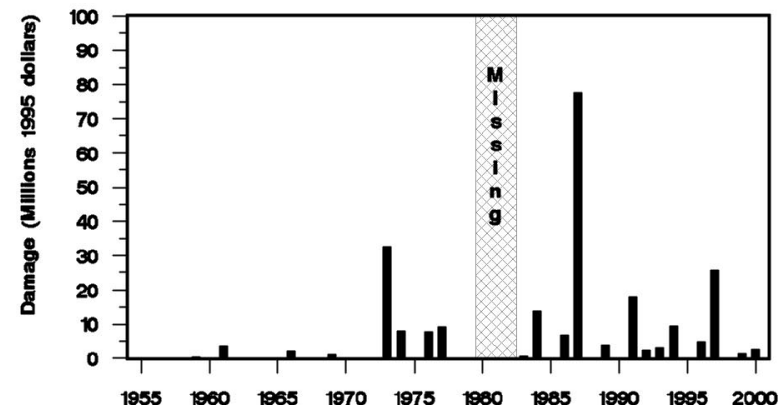

Fig. 5. Historical flood damage in states representing different levels of vulnerability: (a) high vulnerability, California; (b) medium vulnerability, Alabama; (c) low vulnerability, Maine. Estimates are for calendar years 1955-1978 and for water years 1983-2000.

age estimates and therefore less tendency for errors to average out.

For low-vulnerability regions, spatial aggregation can be used to reduce the impact of errors and omissions. Contiguous regional groupings of states with similar frequency distributions are suggested in the second column of Table 2. For example, estimates of damage in New England are expected to be more reliable than estimates of damage in Maine. Other groupings might be appropriate, depending on the purpose of a particular analysis.

\section{Comparing States}

Comparing states on the basis of their historical flood damage is complicated by the rarity of extreme damage. In a limited time period of study, some states will have experienced a lowprobability flood event and others will not. Damage totals for the period depend greatly on a few extreme events. Although aggregating state damage estimates over many years helps reduce estimation errors, it does not account for the sporadic timing of severe damage. 
Table 3. Levels of Annual State Flood Damage in Three States during All Years, 1955-1978 and 1983-1999

\begin{tabular}{|c|c|c|c|c|c|c|}
\hline \multirow[b]{3}{*}{ Annual state flood damage level } & \multicolumn{6}{|c|}{ Flood damage estimates (millions of 1995 dollars) } \\
\hline & \multicolumn{2}{|c|}{$\begin{array}{c}\text { California } \\
\text { (high vulnerability) }\end{array}$} & \multicolumn{2}{|c|}{$\begin{array}{c}\text { Alabama } \\
\text { (medium vulnerability) }\end{array}$} & \multicolumn{2}{|c|}{$\begin{array}{c}\text { Maine } \\
\text { (low vulnerability) }\end{array}$} \\
\hline & $N$ & Sum of damages & $N$ & Sum of damages & $N$ & Sum of damages \\
\hline Over $\$ 1$ billion & 3 & $5,008.4(47.4 \%)$ & 0 & - & 0 & - \\
\hline$\$ 100-1,000$ million & 10 & $4,873.8(46.1 \%)$ & 3 & $601.86(59.6 \%)$ & 0 & - \\
\hline$\$ 10-100$ million & 14 & $657.9(6.2 \%)$ & 13 & $332.89(33.0 \%)$ & 5 & $167.66(72.3 \%)$ \\
\hline$\$ 1-10$ million & 7 & $22.4(0.2 \%)$ & 17 & $72.81(7.2 \%)$ & 13 & $63.25(27.3 \%)$ \\
\hline$\$ 0.1-1$ million & 2 & $1.1(0.0 \%)$ & 4 & $1.82(0.2 \%)$ & 2 & $0.81(0.3 \%)$ \\
\hline$\$ 0.1$ million or less & 2 & $0.1(0.0 \%)$ & 0 & - & 1 & $0.06(0.0 \%)$ \\
\hline Missing & 3 & - & 4 & - & 20 & - \\
\hline Totals & 41 & $10,563.7(100.0 \%)$ & 41 & $1,009.38(100.0 \%)$ & 41 & $231.78(100.0 \%)$ \\
\hline
\end{tabular}

Rankings of states by their total flood damage can differ greatly, depending on the time period covered. A comparison of separate rankings for the periods 1955-1978 and 1983-1999 shows that Pennsylvania suffered the greatest damage in the earlier period, while its rank slips to 26th in the later period. Iowa moves in the opposite direction, from 28 th in the earlier period to first in the later period. In both states, a single flood event determines the first-ranked status.

Depending on the application, it might be important to consider population, wealth, or geographical area when comparing states. For example, per capita damage is better than total damage as an indicator of losses suffered by the populace and the state's ability to cope. In Fig. 6, states are ranked according to their total damage per capita during 1983-2000 (based on population in 2000 ). North Dakota moves to the top, with $\$ 6,417$ damage per person in that period (mostly attributable to flooding in 1997). Fig. 7 shows the level of damage per capita for each state. By this metric, most of the Mississippi River basin would be considered a high-damage area. Comparison with Fig. 4 shows that several states categorized as "low vulnerability" on the basis of median annual damage had a high level of per capita damage during 1983-2000.

\section{Interannual Variations and Comparing Individual Floods}

Individual floods should be compared only in general terms. For example, in California [Fig. 5(a)] flooding clearly caused more damage in 1995 and 1997 than in 1992 and 1993. But the NWS estimates are not accurate enough to say with confidence that 1997 floods caused more damage than those in 1995, or that 1993 floods caused more damage than those in 1992. Other information would be needed to support such conclusions. Typically, a state or river basin suffers little flood damage in most years and severe damage in only a few years [e.g., Figs. 5(b and c)]. In times of relatively low damage, year-to-year variability in the NWS damage estimates is likely to be dominated by estimation errors.

Even in major floods where estimates are highly aggregated, comparisons are hampered by poor accuracy. Some of the difficulties are illustrated by the following comparison of two years of major flood damage in Minnesota in the 1990s.

- 1993: Unusually heavy rainfall from May through August over most of the state produced widespread flooding that resulted in a presidential disaster declaration for 57 of Minnesota's 87 counties and an agricultural disaster declaration for an addi- tional 8 counties. The NWS estimated damage of $\$ 1.0$ billion (in 1995 dollars).

- 1997: Heavy snow and ice followed by spring rains and rapid snowmelt led to severe flooding in April and May. Damage was extensive in East Grand Forks and many smaller communities. A presidential disaster declaration was issued covering 58 Minnesota counties. Additional storms and flooding in June and July led to another disaster declaration for 7 metropolitan

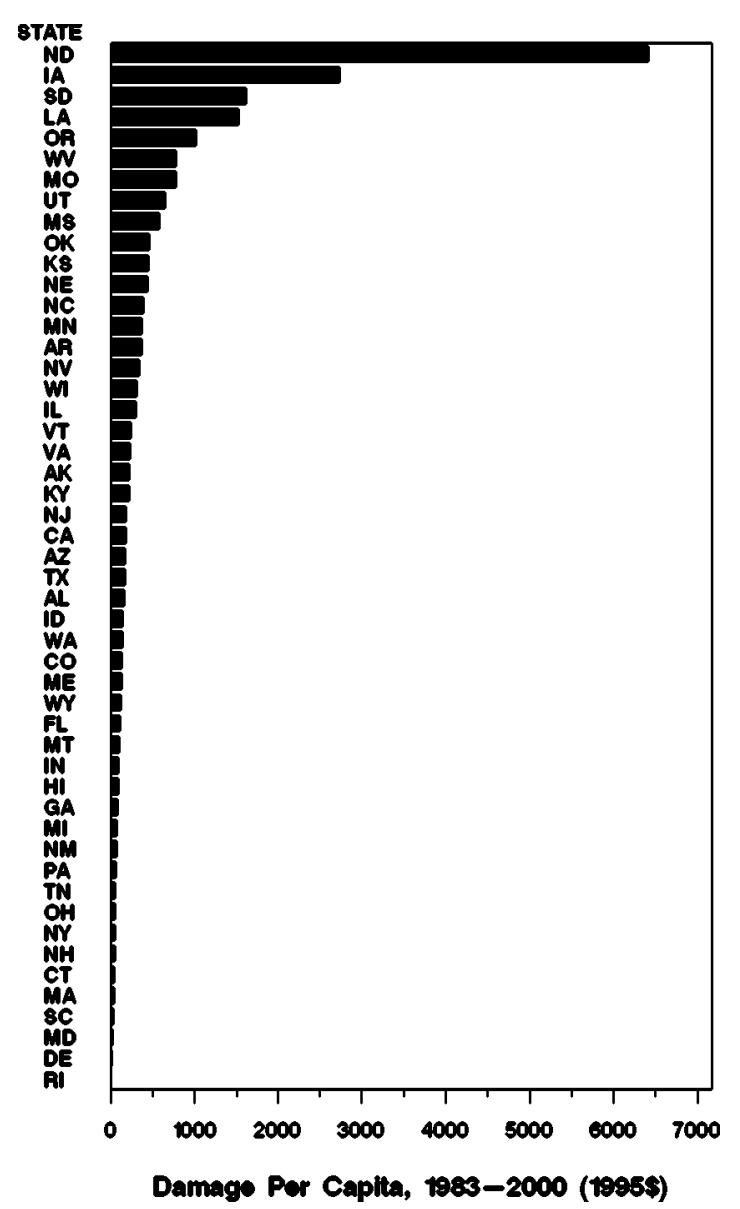

Fig. 6. States ranked by total flood damage per capita (in 1995 dollars) during 1983-2000, based on population in year 2000 


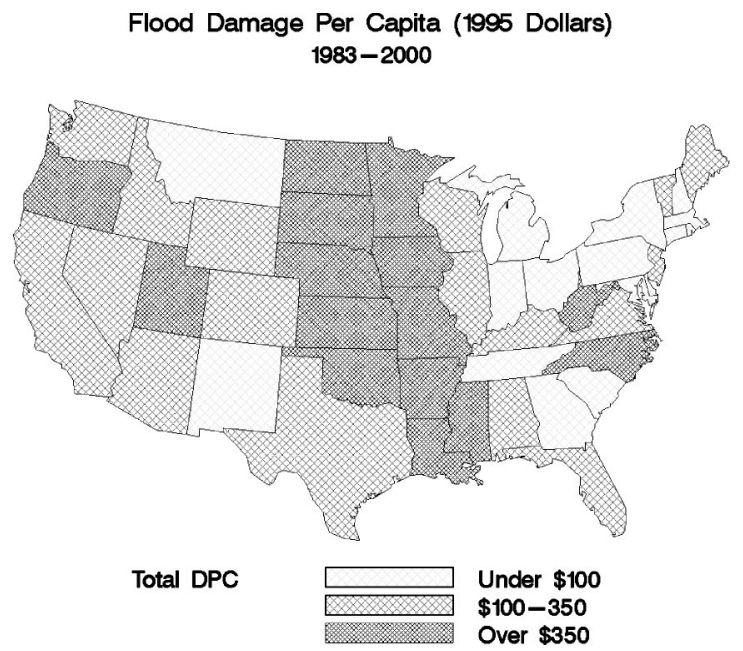

Fig. 7. Level of damage per capita (in 1995 dollars) in each state during 1983-2000

area counties. The NWS estimated damage of $\$ 715$ million (in 1995 dollars).

In which year was the damage more severe? The answer to this question depends on one's interpretation of the events. The NWS estimates suggest that damage was substantially greater in 1993. However, a report issued by the Minnesota Department of Public Safety leads to the opposite conclusion. Table 4 shows actual costs reported in A Decade of Minnesota Disasters (MDPS 2000). (Costs not associated with direct damage have been excluded, such as temporary housing, hazard mitigation, and economic injury due to loss of business.) FEMA assistance programs, insurance, and SBA loans all indicate that nonagricultural losses were much higher in 1997 than in 1993. A representative of Minnesota's Division of Emergency Management reinforced this conclusion, explaining that in 1997 entire Minnesota towns were flooded, while in 1993 the main effects of the great Midwest flood occurred in states farther south (S. Neudahl, personal communication, October 5, 2000).

Agricultural damage was greater in 1993 than in 1997, however. Twice as much money was awarded in FSA loans to Minnesota farmers in 1993 as in 1997 (Table 4). The value of Min-

Table 4. Minnesota Flood Damage Expenditures in Major Flood Years 1993 and 1997 (in Millions of 1995 Dollars)

\begin{tabular}{lcc}
\hline Type of expenditure & 1993 & 1997 \\
\hline Disaster costs itemized by Minnesota Department of Public Safety & \\
Federal, state, and local government direct costs & & \\
associated with FEMA assistance programs & & \\
(excluding temporary housing and hazard mitigation) & 129.7 & 404.3 \\
$\quad$ Insured losses (estimate) & 73.0 & 154.0 \\
$\quad$ Total direct damage costs (nonagricultural) & 202.7 & 558.3 \\
Small Business Administration loans to cover physical damage & \\
$\quad$ SBA physical damage loans for homes and & 16.0 & 74.6 \\
businesses & & \\
U.S. Department of Agriculture loans to farmers, year following & \\
disaster & & \\
$\quad$ Emergency loans through the Farm Service Agency & 21.2 & 10.3
\end{tabular}

Note: Source is MDPS (2000).

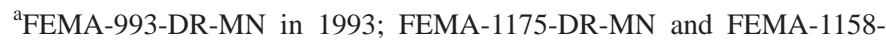
DR-MN in 1997. nesota's final crop output in 1993 was $44 \%$ less than the average of the previous three years (USDA 2000). In contrast, final crop output in 1997 was equal to the average for the previous three years, suggesting that the floods did little to diminish agricultural productivity that year.

This comparison does not lead us to challenge the NWS estimates for these two flood years. Rather, it provides another reason for caution in interpreting and comparing damage estimates. Given the typical disagreements between damage estimates found in this study, the difference of $40 \%$ in estimates for the two years is not large enough to say with confidence that one year's economic damage was worse than the other's, only that there was major damage in both years. Most Minnesotans would probably consider the floods of 1997 to be much more severe than those of 1993, while farmers might hold the opposite view.

Thus, to compare damage in individual flood events, coarse comparisons are advisable based on broad categories such as low, medium, high, and major damage levels. When comparing floods at the county level, where damage estimates are extremely unreliable, damage categories can be based on descriptive information instead of dollar estimates. This approach was used in a study of flooding in two Iowa counties (Pielke et al. 2000).

\section{Possible Inconsistencies with Other Sources}

The NWS defines flood damage more narrowly than many other agencies. Emergency management agencies generally include both river and coastal flooding whenever water rises to overflow land that is not normally submerged. In contrast, the NWS estimates include only flooding whose primary cause is rainfall, snowmelt, or river flows, excluding flooding caused by winddriven waves associated with coastal storms or hurricanes. For example, FEMA records show a presidential disaster declaration of type "flood" for Massachusetts in February 1978, and the USACE reports $\$ 520$ million flood damage due to storm surge and huge waves (USACE 1979, converted to 1995 dollars), but that damage is not included in NWS flood damage estimates.

The NWS estimates do include floods caused by dam failure, however. In the NWS record, Idaho's worst flood resulted from the failure in 1976 of the newly constructed Teton Dam, with damage estimates in the $\$ 1$ billion to 2.3 billion range (Chadwick et al. 1976, converted to 1995 dollars). Idaho's largest estimated flood damage due to natural causes was much smaller: \$120 million in 1997.

\section{Recommendations for Users}

Although far from perfect, these data sets are the most complete and consistent available records of historical flood damage in the United States, and do contain useful information. Users of the data are warned to keep the weaknesses in mind when attempting to draw conclusions. Most notably, the damage estimates are collected from diverse sources by staff with little or no training in damage estimation and are not compared with actual costs. They do not include all of the losses that might be attributable to flooding; rather, they are rough estimates of direct physical damage to property, crops, and public infrastructure. Damage estimates for individual flood events are often quite inaccurate. However, as estimates from many events are added together the errors become proportionately smaller. The following procedures are recommended when using the reanalyzed NWS flood damage estimates. 1. When comparing national flood damage over time, reason- 
able consistency in annual damage estimates can be assumed during the years 1934-1979 and 1983-2000. Adjustment for changes in population, wealth, or development is advisable.

2. To determine the frequency of damaging floods in a state or region, establish a threshold below which estimates are simply classified as "low" or "minimal" and report the frequency of floods that exceed the threshold.

3. To reduce the impact of estimation errors at the state level (especially in regions where damage estimates tend to be low), aggregate estimates over space or time. To compare damage between years, one can aggregate state damage estimates over multistate regions. To compare damage between states or regions, one can aggregate the estimates over many years and compare the sums. Even when the estimates are highly aggregated, be aware that some of the variability is caused by estimation errors and interpret the results accordingly.

4. When comparing flood damage between states or regions, consider the effect of differences in population, wealth, geographic area, or incidence of extreme weather events during the period of study. Depending on the application, it could be important to control for some of these intervening variables.

5. When comparing individual floods in a state, use of broad categories such as low, medium, high, and major damage levels is advisable. To compare floods of a similar magnitude, look for qualitative descriptions of the nature and impacts of the damage.

6. Check for incompatibilities before combining damage estimates from different sources. For example, different agencies define "flood" and "flood damage" somewhat differently.

With the cautions noted above, the reanalyzed NWS flood damage estimates can be a valuable tool to aid researchers and decision makers in understanding the changing character of damaging floods in the United States. However, the estimates are not accurate enough to serve as a basis for detailed evaluation of flood policies.

Looking forward, the results of this study underscore previous calls for complete and reliable data on losses related to natural hazards [e.g., Mileti (1999); NRC (1999); Heinz Center (2000); Changnon (2003)]. The National Research Council (NRC 1999) observes that such loss data are critical for effective policy making related to hazards. And RAND (Meade and Abbott 2003) observes that priority setting for natural hazards-related research would be facilitated with improved data on losses. Until such improved data sets are available, it is important to make the most effective use of available data from the historical record.

\section{Acknowledgments}

The writers are grateful for assistance and information provided by NWS staff members Frank Richards, Joanna Dionne, Paul Polger, John Ogren, Robert Glancy, and Frank Cooper. Many state emergency management agencies also provided information for this study. Richard Katz, D. Jan Stewart, and two anonymous reviewers provided helpful comments on earlier drafts of the manuscript. Jennifer Oxelson created the Web site 〈www.flooddamagedata.org,, making the reanalyzed data publicly available. This work was supported in part by the National Oceanic and Atmospheric Administration, Office of Global Programs, Grant No. NA96GP0451. The National Center for Atmospheric Research is supported by the National Science Foundation.

\section{References}

Chadwick, W. L., et al. (1976). Rep. to U.S. Dept. of Interior and State of Idaho on Failure of Teton Dam. U.S. Government Printing Office, Washington, D.C.

Changnon, S. D. (2003). "Measures of economic impacts of weather extremes: Getting better but far from what is needed-A call for action." Bull. AMS, 84(9), 1231-1235.

Downton, M. W. and Pielke, R. A., Jr. (2005). "How accurate are disaster loss data? The case of U.S. flood damage." Natural Hazards (in press).

Heinz Center. (2000). The hidden costs of coastal hazards: Implications for risk assessment and mitigation. Island Press, Washington, D.C.

Meade, C., and Abbott, M. (2003). Assessing federal research and development for hazard loss reduction, RAND, Santa Monica, Calif.

Mileti, D. S. (1999). Disasters by design: A reassessment of natural hazards in the United States, Joseph Henry Press, Washington, D.C.

Minnesota Department of Public Safety (MDPS). (2000). A decade of Minnesota disasters: A historical look at Minnesota disasters in the 1990s, Minnesota Dept. of Public Safety, Div. of Emergency Management, St. Paul, Minn.

National Research Council (NRC). (1999). The impacts of natural disasters: A framework for loss estimation, National Academy Press, Washington, D.C.

National Weather Service (NWS). (1977). Climatological data national summary, Asheville, N.C. (for 1975 and 1977).

National Weather Service (NWS). (2004). "Flood losses: Compilation of flood loss statistics." 〈http://nws.noaa.gov/oh/hic/flood_stats/ Flood_loss_time_series.shtml $\rangle$ (Jan. 6, 2004).

Pielke, R. A., Jr. and Downton, M. W. (2000). "Precipitation and damaging floods: Trends in the United States, 1932-1997." J. Clim., 13(20), 3625-3637.

Pielke, R. A., Jr., Downton, M. W., and Miller, J. Z. B. (2002). Flood damage in the United States, 1926-2000: A reanalysis of National Weather Service estimates, National Center for Atmospheric Research, Boulder, Colo.

Pielke, R. A., Jr., Downton, M. W., Miller, J. Z. B., Changnon, S. A., Kunkel, K. E., and Andsager, K. (2000). Understanding damaging floods in Iowa: Climate and societal interactions in the Skunk and Raccoon river basins, Electric Power Research Institute, Palo Alto, Calif.

U.S. Army Corps of Engineers (USACE). (1979). A Rep. on the Assessment of Flood Damages Resulting from the Storm of 6-7 February 1978 along the Coastline from Orleans, Massachusetts to New Castle, New Hampshire. New England Division, Waltham, Mass.

U.S. Army Corps of Engineers (USACE). (1984-2002, passim). Army Corps of Engineers Annual Flood Damage Rep. to Congress, U.S. Government Printing Office, Washington, D.C. (for 1984-2002).

U.S. Department of Agriculture (USDA). (2000). "Value added to the U.S. economy by the agricultural sector via the production of goods and services, 1990-1999, Minnesota." 〈http:// usda.mannlib.cornell.edu/> (Oct. 9, 2000). 